\title{
Gonadotropin treatment increases homocysteine levels in idiopathic hypogonadotropic hypogonadism: an indirect effect mediated by changes in body composition
}

\author{
C Oktenli, Z Yesilova ${ }^{1}$, M Ozata ${ }^{2}$, H Yaman $^{3}$, A Tuzun ${ }^{1}$, \\ S Dundar ${ }^{4}$, S Y Sanisoglu ${ }^{5}$, U Musabak $^{6}$, M K Erbil $^{3}$ and \\ K Dagalp ${ }^{1}$
}

Department of Internal Medicine, Gülhane Military Medical Academy, TR-06018 Etlik-Ankara, Turkey

${ }^{1}$ Department of Gastroenterology, Gülhane Military Medical Academy, Ankara, Turkey

${ }^{2}$ Department of Endocrinology and Metabolism, Gülhane Military Medical Academy, Etlik, Ankara, Turkey

${ }^{3}$ Department of Biochemistry, Gülhane Military Medical Academy, Etlik, Ankara, Turkey

${ }^{4}$ Department of Nuclear Medicine, Gülhane Military Medical Academy, Etlik, Ankara, Turkey

${ }^{5}$ Department of Biostatistics, Gülhane Military Medical Academy, Etlik, Ankara, Turkey

${ }^{6}$ Department of Immunology, Gülhane Military Medical Academy, Etlik, Ankara, Turkey

(Requests for offprints should be addressed to C Oktenli; Email: coktenli@gata.edu.tr or coktenli@ttnet.net.tr)

\begin{abstract}
The main objective of the present study was to examine the alterations in plasma total homocysteine (tHcy) concentrations during a testosterone-deficient state and after gonadotropin treatment for 6 months in patients with idiopathic hypogonadotropic hypogonadism (IHH). Thirty-five newly diagnosed male patients with IHH (mean age $21.34 \pm 1.53$ years) and 29 age- and body mass index-matched healthy males (mean age 21.52 \pm 1.77 years) were recruited into the study. Pretreatment levels of free testosterone $(1.51 \pm 0.66 \mathrm{pg} / \mathrm{ml})$, estradiol $(21.37 \pm$ $4 \cdot 37 \mathrm{pg} / \mathrm{ml})$, FSH $(0 \cdot 91 \pm 0 \cdot 24 \mathrm{IU} / \mathrm{l})$ and $\mathrm{LH}(1 \cdot 25 \pm$ $0 \cdot 53 \mathrm{IU} / \mathrm{l})$ were lower than controls $(25 \cdot 17 \pm 3 \cdot 06 \mathrm{pg} / \mathrm{ml}$, $31.00 \pm 4.96 \mathrm{pg} / \mathrm{ml}, 3.14 \pm 1.62 \mathrm{IU} / 1$ and $4.83 \pm 1.65$ IU/1 respectively) $(P<0 \cdot 001)$. They increased significantly after treatment $(18.18 \pm 1.59 \mathrm{pg} / \mathrm{ml}, 27.97 \pm$ $4 \cdot 25 \mathrm{pg} / \mathrm{ml}, \quad 2 \cdot 41 \pm 0 \cdot 27 \mathrm{IU} / 1$ and $2 \cdot 79 \pm 0 \cdot 19 \mathrm{IU} / 1$ respectively) $(P<0 \cdot 001)$. Patients with $\mathrm{IHH}$ had lower tHcy levels than controls $(10 \cdot 14 \pm 1.34$ and $12.58 \pm$ $2 \cdot 29 \mu \mathrm{mol} / 1$ respectively $)(P<0 \cdot 001)$. Plasma tHcy concentrations increased significantly $(12.63 \pm 1.44 \mu \mathrm{mol} / \mathrm{l})$ after 6 months of treatment $(P<0 \cdot 001)$. As compared with the controls, pretreatment levels of serum creatinine
\end{abstract}

$(63 \cdot 54 \pm 13 \cdot 01$ vs $82 \cdot 84 \pm 16 \cdot 69 \mu \mathrm{mol} / \mathrm{l})$, hemoglobin $(12.98 \pm 0.56$ vs $13.83 \pm 0.71 \mathrm{~g} / \mathrm{dl})$ and hematocrit $(39 \cdot 29 \pm 2 \cdot 01$ vs $41 \cdot 38 \pm 1 \cdot 95 \%)$ were significantly lower $(P<0 \cdot 001)$, and they increased significantly following treatment $(80.24 \pm 11.93 \mu \mathrm{mol} / \mathrm{l}, 13.75 \pm 0.49 \mathrm{~g} / \mathrm{dl}$ and $41 \cdot 26 \pm 1 \cdot 78 \%$ respectively $)(P<0 \cdot 001)$. The pretreatment folic acid and vitamin $B_{12}$ levels were significantly higher in patients when compared with controls $(14.87 \pm 5.68$ vs $12.52 \pm 4.98 \mathrm{nmol} / 1, \quad P=0.034$ and $289 \cdot 75 \pm 92 \cdot 34$ vs $237 \cdot 59 \pm 108 \cdot 17 \mathrm{pmol} / 1, \quad P=0.002$ respectively). They decreased significantly after treatment $(11 \cdot 29 \pm 3 \cdot 31 \mathrm{nmol} / 1$ and $228 \cdot 51 \pm 54.33 \mathrm{pmol} / 1 \mathrm{respec}-$ tively) $(P<0 \cdot 001)$. The univariate and multivariate regression analysis results showed that only changes in creatinine, creatinine clearance, vitamin $\mathrm{B}_{12}$ and folic acid were independently associated with changes in tHcy levels in patients with IHH. In conclusion, the increase in plasma tHcy concentrations following gonadotropin treatment seems to be largely independent of changes in androgen levels.

Journal of Endocrinology (2003) 179, 35-39

\section{Introduction}

There is a consistent body of evidence from studies indicating that fasting plasma total homocysteine (tHcy) concentrations are higher in men than in women, which has led to the suggestion that sex steroid hormones may influence tHcy levels (Jacobsen et al. 1994, van der
Mooren et al. 1994). Moreover, plasma tHcy levels were decreased by the administration of ethinyl estradiol and anti-androgen to male transsexual subjects and increased by the administration of androgen to female transsexual subjects (Giltay et al. 1998). Recently, high plasma tHcy levels were reported in patients with polycystic ovary syndrome (PCOS), a state characterized by high levels of 
endogenous testosterone (Yarali et al. 2001). Furthermore, Ebenbichler et al. (2001) have also suggested that intake of anabolic androgenic steroids, as used by bodybuilders, induces hyperhomocysteinemia.

The long-term effects of androgens on plasma tHcy concentrations in humans is not difficult to study because there are at least two hypogonadal syndromes in men who have testosterone deficiency and require hormone replacement therapy. However, to our knowledge, there have been no reports on the effect of gonadotropin treatment on tHcy concentrations in idiopathic hypogonadotropic hypogonadism (IHH). In the present study, therefore, we had the following two objectives: (1) to examine the alterations in fasting plasma tHcy concentrations during a testosterone-deficient state in patients with $\mathrm{IHH}$; and (2) to find out whether there is any effect of gonadotropin treatment on tHcy levels in these patients.

\section{Materials and Methods}

Subjects

Thirty-five newly diagnosed male patients with $\mathrm{IHH}$, and 29 sex-, age- and body mass index (BMI)-matched healthy raw recruits were enrolled in the study. The diagnosis of IHH was based on failure to undergo spontaneous puberty before 18 years of age and was confirmed by a decreased serum testosterone concentration below the normal range for adults, follicle-stimulating hormone (FSH) and luteinizing hormone (LH) levels within or below the normal range, absence of a pituitary or hypothalamic mass lesion on computed tomography or magnetic resonance imaging, presence of a gonadotropin response to repetitive doses of gonadotropin-releasing hormone, normal smell test and normal karyotypes (46, XY).

None of the patients had hyposmia, anosmia or a family history of IHH. All patients had scrotal testes. All controls had a history of spontaneous puberty and their physical and biochemical findings were within the normal range. Patients and controls who reported a history of renal, hepatic and vascular diseases, diabetes mellitus, hypertension, hyperlipidemia, malignancies, anemia, hypothyroidism, intake of androgen, thiazide diuretics, phenytoin, carbamazepine, theophylline, nitrous oxide, metformin, niacin, penicillamine, methotrexate, vitamin $\mathrm{B}_{6}$, vitamin $\mathrm{B}_{12}$ and/or folic acid supplements, excessive coffee consumption, chronic alcohol intake and current smoking were excluded. Strenuous physical activity was not allowed before the collection of blood samples.

All patients and control subjects were informed about the aim and procedures of the study and gave their consent. The study was approved by the Ethical Committee of Gülhane Military Medical Academy.

\section{Study design}

Patients were treated with human chorionic gonadotropin (hCG; Profasi HP 2000; Serona SA, Aubonne,
Switzerland; containing 2000 IU hCG) and human postmenopausal gonadotropin (Pergonal; Serona SA; containing $75 \mathrm{IU}$ FSH and 75 IU LH) three times a week for 6 months. Hormonal and biochemical data were assessed 6 months after therapy in all patients.

Fasting blood samples were collected from patients and controls between 0800 and $0830 \mathrm{~h}$ after overnight fasting. Post-treatment blood samples were drawn 7 days after the final injection of gonadotropin. Venous blood samples were centrifuged within less than $60 \mathrm{~min}$, which is sufficient to prevent an increase in plasma homocysteine resulting from ex vivo generation of homocysteine by erythrocytes. Plasma was stored at $-80{ }^{\circ} \mathrm{C}$ until homocysteine was measured.

Assays

Plasma tHcy concentrations were measured by high performance liquid chromatography (HPLC; Millipore Corp., Waters Chromatography Division, Milford, MA, USA) (Araki \& Sako 1987). The intra- and interassay coefficients of variation (CV) were $1.96 \%$ and $2.43 \%$ respectively. Vitamin $\mathrm{B}_{12}$ and folic acid levels were measured by RIA with reagents from Diagnostic Product Corp. (Los Angeles, CA, USA). The intra- and interassay CV values were $3 \cdot 73 \%$ and $4 \cdot 79 \%$ for vitamin $B_{12}$ and $3 \cdot 3 \%$ and $3 \cdot 8 \%$ for folic acid respectively.

Complete blood count analyses were performed with an automatic hemocounter (Cell-Dyn 1700; Abbott, Santa Clara, CA, USA). Total plasma cholesterol, albumin and triglyceride were measured by an enzymatic calorimetric method with an Olympus AU 600 autoanalyzer using reagents from Olympus Diagnostics, GmbH (Hamburg, Germany). Serum creatinine levels were determined using a modified kinetic Jaffé method (Cook 1971).

Creatinine clearance was calculated according to the modified Cockcroft-Gault formula (Cockcroft \& Gault 1976): $[140$ - age (years) $] \cdot$ weight $(\mathrm{kg}) \cdot(1,22) /$ serum creatinine $(\mu \mathrm{mol} / \mathrm{l})$.

Serum FSH, LH, estradiol and prolactin (PRL) concentrations were measured by immunoradiometric assay with reagents from Radim Techland (Angleur, Belgium). The intra- and interassay CV values were $4 \cdot 4 \%$ and $6.0 \%$ for FSH, $4.8 \%$ and $5.4 \%$ for $\mathrm{LH}, 4.4 \%$ and $6.0 \%$ for estradiol and $4.6 \%$ and $6.0 \%$ for PRL. Serum free testosterone concentrations were determined by a solid-phase ${ }^{125}$ I RIA with reagents from Diagnostic Product Corp. The intraand interassay $\mathrm{CV}$ values for free testosterone were 3.8\% and $4 \cdot 2 \%$. Serum sex hormone binding globulin (SHBG) levels were measured by RIA with reagent from Radim Techland. The intra- and interassay CV values for SHBG were $2 \cdot 4 \%$ and $2 \cdot 9 \%$. The normal ranges in our laboratory are $9 \cdot 27-14 \cdot 01 \mu \mathrm{mol} / 1$ for $\mathrm{tHcy},<15 \mathrm{IU} / 1$ for FSH, $<20$ IU/1 for $\mathrm{LH},<60 \mathrm{pg} / \mathrm{ml}$ for estradiol, $15-45 \mathrm{pg} / \mathrm{ml}$ for free testosterone and $9-38 \mathrm{nmol} / \mathrm{l}$ for SHBG. The upper limit for PRL is $12 \mu \mathrm{g} / 1$. 
Table 1 Clinical and laboratory features of patients with $\mathrm{IHH}$ and controls. Values are means \pm S.D.

\begin{tabular}{|c|c|c|c|c|c|}
\hline & Controls $(n=29)$ & Pretreatment & $\begin{array}{l}\text { IHH }(n=35) \\
\text { Post-treatment }\end{array}$ & $\begin{array}{l}\text { Controls vs IHH } \\
\text { (pretreatment) } \\
(P)\end{array}$ & $\begin{array}{l}\text { Pre- vs post- } \\
\text { treatment } \\
(P)\end{array}$ \\
\hline \multicolumn{6}{|l|}{ Parameters } \\
\hline Age (years) & $21 \cdot 52 \pm 1 \cdot 77$ & $21 \cdot 34 \pm 1 \cdot 53$ & & $0 \cdot 674^{\mathrm{a}}$ & \\
\hline BMI $\left(\mathrm{kg} / \mathrm{m}^{2}\right)$ & $20 \cdot 48 \pm 1 \cdot 05$ & $19.94 \pm 2.65$ & $21 \cdot 00 \pm 1 \cdot 81$ & $0 \cdot 210^{\mathrm{a}}$ & $0.001^{d}$ \\
\hline Hemoglobin (g/dl) & $13 \cdot 83 \pm 0 \cdot 71$ & $12.98 \pm 0.56$ & $13 \cdot 75 \pm 0 \cdot 49$ & $<0 \cdot 001^{\mathrm{a}}$ & $<0.001^{\mathrm{c}}$ \\
\hline Hematocrit (\%) & $41 \cdot 38 \pm 1.95$ & $39 \cdot 29 \pm 2 \cdot 01$ & $41 \cdot 26 \pm 1 \cdot 78$ & $<0.001^{\mathrm{a}}$ & $<0.001^{d}$ \\
\hline Creatinine $(\mu \mathrm{mol} / \mathrm{l})$ & $82 \cdot 84 \pm 16 \cdot 69$ & $63 \cdot 54 \pm 13 \cdot 01$ & $80 \cdot 24 \pm 11 \cdot 93$ & $<0.001^{b}$ & $<0.001^{d}$ \\
\hline Creatinine clearance $(\mathrm{ml} / \mathrm{min})$ & $128 \cdot 38 \pm 23 \cdot 56$ & $153 \cdot 80 \pm 26 \cdot 48$ & $131 \cdot 46 \pm 23 \cdot 44$ & $<0 \cdot 001^{\mathrm{a}}$ & $<0.001^{\mathrm{c}}$ \\
\hline Plasma albumin $(\mathrm{g} / \mathrm{l})$ & $38 \cdot 03 \pm 1 \cdot 15$ & $37 \cdot 69 \pm 1 \cdot 11$ & $38 \cdot 16 \pm 1 \cdot 25$ & $0 \cdot 385^{\mathrm{b}}$ & $0 \cdot 125^{\mathrm{c}}$ \\
\hline Total cholesterol $(\mathrm{mmol} / \mathrm{l})$ & $4 \cdot 42 \pm 0 \cdot 85$ & $4.63 \pm 0.99$ & $4 \cdot 88 \pm 0 \cdot 86$ & $0 \cdot 539^{a}$ & $0.069^{c}$ \\
\hline Triglyceride $(\mathrm{mmol} / \mathrm{l})$ & $1 \cdot 09 \pm 0 \cdot 18$ & $1 \cdot 02 \pm 0 \cdot 40$ & $1 \cdot 04 \pm 0.37$ & $0.079^{b}$ & $0 \cdot 324^{d}$ \\
\hline Free testosterone $(\mathrm{pg} / \mathrm{ml})$ & $25 \cdot 17 \pm 3 \cdot 06$ & $1.51 \pm 0.66$ & $18 \cdot 18 \pm 1 \cdot 59$ & $<0.001^{\mathrm{a}}$ & $<0.001^{\mathrm{d}}$ \\
\hline $\mathrm{FSH}(\mathrm{IU} / \mathrm{I})$ & $3 \cdot 14 \pm 1 \cdot 62$ & $0.91 \pm 0.24$ & $2 \cdot 41 \pm 0 \cdot 27$ & $<0 \cdot 001^{b}$ & $<0.001^{d}$ \\
\hline $\mathrm{LH}(\mathrm{IU} / \mathrm{I})$ & $4 \cdot 83 \pm 1 \cdot 65$ & $1 \cdot 25 \pm 0.53$ & $2 \cdot 79 \pm 0 \cdot 19$ & $<0 \cdot 001^{\mathrm{a}}$ & $<0.001^{\mathrm{c}}$ \\
\hline Estradiol (pg/ml) & $31 \cdot 00 \pm 4.96$ & $21 \cdot 37 \pm 4 \cdot 37$ & $27 \cdot 97 \pm 4 \cdot 25$ & $<0 \cdot 001^{\mathrm{a}}$ & $<0.001^{\mathrm{c}}$ \\
\hline SHBG $(\mathrm{nmol} / \mathrm{l})$ & $26 \cdot 93 \pm 5 \cdot 80$ & $40 \cdot 44 \pm 13 \cdot 12$ & $35.63 \pm 8.63$ & $<0.001^{\mathrm{b}}$ & $0 \cdot 222^{\mathrm{c}}$ \\
\hline $\mathrm{PRL}(\mu \mathrm{g} / \mathrm{l})$ & $6 \cdot 24 \pm 1 \cdot 88$ & $6 \cdot 86 \pm 1 \cdot 22$ & $6.84 \pm 0.97$ & $1 \cdot 119^{a}$ & $0.923^{\mathrm{c}}$ \\
\hline $\mathrm{tHcy}(\mu \mathrm{mol} / \mathrm{l})$ & $12 \cdot 58 \pm 2 \cdot 29$ & $10 \cdot 14 \pm 1 \cdot 34$ & $12 \cdot 63 \pm 1 \cdot 44$ & $<0 \cdot 001^{a}$ & $<0.001^{\mathrm{c}}$ \\
\hline $\mathrm{tHcy} /$ creatinine & $0 \cdot 15 \pm 0.03$ & $0 \cdot 16 \pm 0 \cdot 02$ & $0 \cdot 16 \pm 0 \cdot 01$ & $0 \cdot 141^{a}$ & $0 \cdot 177^{\mathrm{c}}$ \\
\hline Vitamin $B_{12}(\mathrm{pmol} / \mathrm{l})$ & $237 \cdot 59 \pm 108 \cdot 17$ & $289 \cdot 75 \pm 92 \cdot 34$ & $228 \cdot 51 \pm 54 \cdot 33$ & $0 \cdot 002^{\mathrm{a}}$ & $<0.001^{\mathrm{c}}$ \\
\hline Folic acid $(\mathrm{nmol} / \mathrm{l})$ & $12.52 \pm 4.98$ & $14 \cdot 87 \pm 5 \cdot 68$ & $11 \cdot 29 \pm 3 \cdot 31$ & $0 \cdot 034^{\mathrm{b}}$ & $<0.001^{d}$ \\
\hline
\end{tabular}

andependent sample $t$-test; ${ }^{b}$ Mann-Whitney $U$ test; ${ }^{\text {a }}$ paired sample $t$-test; ${ }^{d}$ Wilcoxon signed rank test.

\section{Statistical analysis}

All the statistical analyses were performed by using SPSS 10.0 (SPSSFW; SPSS Inc., Chicago, IL, USA) statistical package. Descriptive statistics are given as the arithmetic mean \pm S.D. First we examined the normality assumptions for the variables by the Kolmogorov-Smirnov test. For the pairwise comparisons we used the paired sample $t$-test when the normality assumptions were held and the Wilcoxon signed rank test otherwise. For the comparison of two groups we used the independent sample $t$-test or the Mann-Whitney $U$ test. Relations among changes in tHcy and the other parameters were investigated by linear regression analysis using the change in tHcy as the dependent variable and the change in sex steroids, vitamin $\mathrm{B}_{12}$, folic acid, creatinine and creatinine clearance as independent variables. After the linear regression analysis, we used multiple regression analysis with a backward stepwise method using the change in tHcy and tHcy/ creatinine ratio as dependent variables and changes in creatinine, testosterone, FSH, LH, estradiol, PRL, folic acid and vitamin $\mathrm{B}_{12}$ as independent factors. In the last stage, we found that creatinine, creatinine clearance, vitamin $B_{12}$ and folic acid were statistically important for the model while the other factors were not. We also calculated the coefficient of determination (adjusted $R^{2}$ ) for the final model. $P$ values less than or equal to 0.05 were evaluated as statistically significant (Zar 1996, Dawson \& Trapp 2001).

\section{Results}

Pre- and post-treatment clinical and laboratory characteristics and the results of comparisons are given in Table 1. BMI was slightly but not significantly $(P=0 \cdot 210)$ lower in untreated patients as compared with controls, whereas it increased significantly after treatment $(P=0 \cdot 001)$. Pretreatment levels of free testosterone, estradiol, FSH and LH were lower than controls $(P<0 \cdot 001)$. They increased significantly after treatment $(P<0 \cdot 001)$. However, creatinine clearance was higher than controls before therapy $(P<0 \cdot 001)$, whereas it decreased significantly $(P<0 \cdot 001)$ after treatment. SHBG was higher than controls before therapy $(P<0 \cdot 001)$, whereas it decreased slightly but not significantly $(P=0 \cdot 222)$ after treatment. PRL levels did not differ significantly between the groups.

As compared with the controls, pretreatment levels of serum creatinine, hemoglobin and hematocrit were significantly lower $(P<0 \cdot 001)$, and they increased significantly following treatment $(P<0 \cdot 001)$. There was no difference between patients and controls with respect to tHcy/creatinine ratio and the mean levels of albumin, total cholesterol and triglyceride.

The pretreatment folic acid and vitamin $B_{12}$ levels were significantly higher in patients when compared with controls $(P=0.034$ and $P=0.002$ respectively). They decreased significantly after treatment $(P<0 \cdot 001)$. A scatter plot of tHcy levels in the controls and patients before and after treatment is shown in Fig. 1. Patients with IHH 


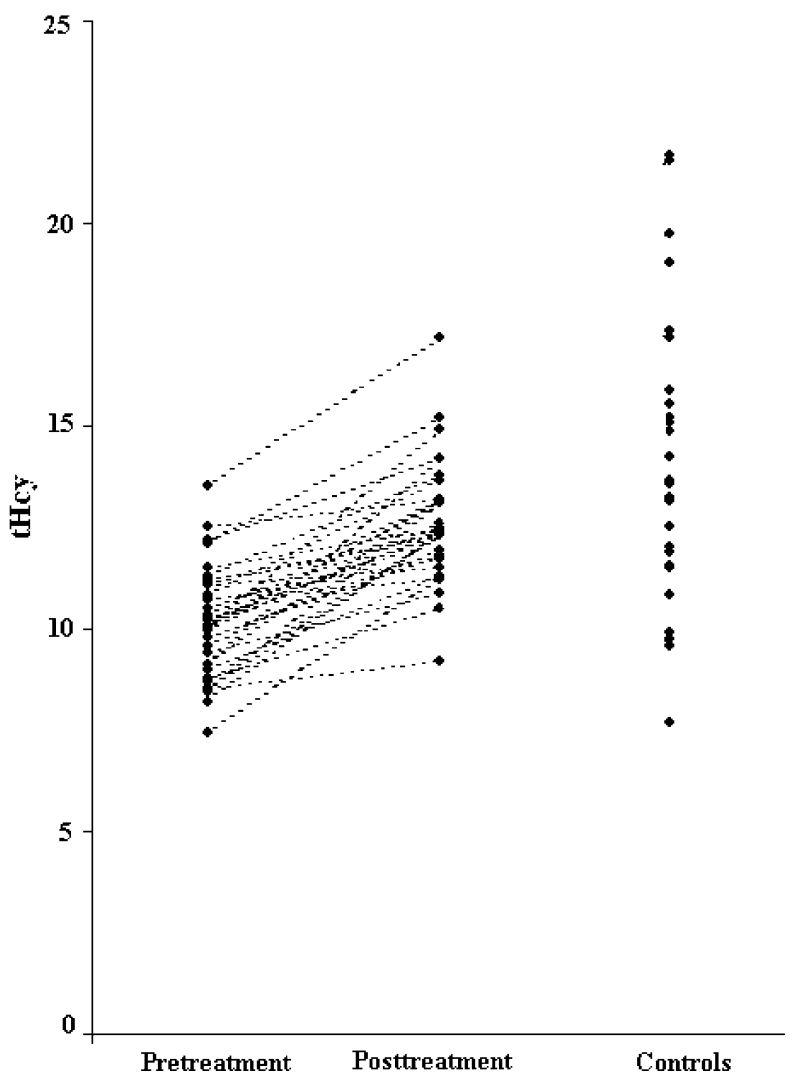

Figure $1 \mathrm{~A}$ scatter plot of thcy levels $(\mu \mathrm{mol} / \mathrm{l})$ in the controls and patients before and after treatment.

had lower tHcy levels than controls $(P<0 \cdot 001)$. However, plasma fasting tHcy concentrations increased significantly $(P<0 \cdot 001)$ after 6 months of treatment (mean increment $24 \cdot 56 \%)$.

The linear and multiple regression analyses in patients with $\mathrm{IHH}$ revealed that only changes in creatinine, creatinine clearance, vitamin $\mathrm{B}_{12}$ and folic acid were independently associated with changes in tHcy levels in patients with IHH (Table 2). These significant associations were consistently present in a multivariate regression analysis.

Table 2 Linear and multiple regression results of the change in tHcy levels of patients with $\mathrm{IHH}$

\begin{tabular}{|c|c|c|c|c|}
\hline & \multicolumn{2}{|c|}{ Linear regression } & \multicolumn{2}{|c|}{ Multiple regression } \\
\hline & Intercept & $P$ & Intercept & $P$ \\
\hline \multicolumn{5}{|l|}{ Factors } \\
\hline Creatinine $(\mu \mathrm{mol} / \mathrm{l})$ & 0.952 & $<0 \cdot 001$ & $0 \cdot 328$ & $<0.001$ \\
\hline $\begin{array}{l}\text { Creatinine clearance } \\
(\mathrm{ml} / \mathrm{min})\end{array}$ & -0.964 & $<0.001$ & $-0 \cdot 447$ & $<0 \cdot 001$ \\
\hline Vitamin $B_{12}(p m o l / l)$ & $-0 \cdot 840$ & -0.001 & $-0 \cdot 109$ & 0.015 \\
\hline Folic acid (nmol/l) & $-0 \cdot 790$ & $<0.001$ & -0.079 & $0 \cdot 038$ \\
\hline Adjusted $R^{2}$ & & & \multicolumn{2}{|c|}{0.984} \\
\hline
\end{tabular}

\section{Discussion}

The present study is the first, to our knowledge, to examine the effects of gonadotropin therapy on tHcy concentrations in patients with $\mathrm{IHH}$. We have shown that the plasma fasting tHcy concentrations in patients with IHH were low during the testosterone-deficient state as compared with controls, whereas a significant increase was observed after gonadotropin treatment. In agreement with our findings, Giltay et al. (1998) reported that plasma tHcy levels increased after androgen administration to female (transsexual) subjects. Ebenbichler et al. (2001) also suggested that the intake of anabolic androgenic steroids induced acute hyperhomocysteinemia. Similarly, high plasma tHcy levels were reported in patients with PCOS (Yarali et al. 2001). In contrast, in a cross-over study, short-term supraphysiological doses of testosterone did not alter fasting plasma tHcy concentrations in 14 normal male weightlifters (Zmuda et al. 1997). However, as indicated by these authors, this study had several limitations. First, a longer treatment duration and larger sample size might be required to reveal a testosterone effect on tHcy levels. Secondly, all subjects in that study had normal testosterone levels.

Our study revealed that plasma tHcy concentration tended to increase with creatinine and with decreasing creatinine clearance, plasma levels of vitamin $\mathrm{B}_{12}$ and folic acid. It seems likely, therefore, that creatinine, creatinine clearance and vitamin status are determining factors for plasma tHcy levels in patients with IHH. These results also suggest that neither sex hormones nor BMI have an important, at least directly, influence on tHcy levels in IHH. In our study, as well as in others (Andersson et al. 1992, Brattstrom et al. 1994), serum creatinine was positively associated with plasma tHcy concentrations. The kidney plays an important role in the metabolism of homocysteine (Arnadottir et al. 1996, Wollesen et al. 1999) and, as such, it would explain not only why renal failure is an important cause of hyperhomocysteinemia, but also why creatinine is one of the biochemical parameters that correlate best with tHcy levels. This is probably due to the requirement, in the synthesis of the precursor of creatinine (creatine), of the donation of methyl groups formed in the transformation of methionine to homocysteine (Mudd \& Poole 1975). In this context, since androgens play an important role in the maintenance of muscle mass (Bhasin et al. 1996, Katznelson et al. 1996), increased turnover of muscle and protein following gonadotropin treatment may be the cause of the increase in creatinine. Furthermore, creatinine clearance was negatively associated with plasma tHcy in patients with IHH. These findings are in agreement with other authors who found strong correlations between tHcy and creatinine clearance (Arnadottir et al. 1996, Wollesen et al. 1999). It is possible that gonadotropin treatment may affect kidney function and it may be an another underlying factor for raised plasma tHcy concentrations following treatment. 
In the current study, as in others (Andersson et al. 1992, Selhub et al. 1993, Ueland et al. 1993, Jacobsen et al. 1994), both vitamin $B_{12}$ and folic acid were negatively associated with plasma tHcy. On the other hand, it has been shown that androgens modulate erythropoietin receptor expression in erythroid cells and that androgens can also directly modulate the hematopoietic system, since androgen receptors have also been shown in erythroid cells of the bone marrow, indicating that androgens may exert direct effects on a wide spectrum of bone marrow cell types via androgen receptor-mediated responses (Jockenhovel et al. 1997). As expected, hemoglobin and hematocrit levels increased significantly after gonadotropin treatment. Since synthesis of homocysteine takes place in erythrocytes to a small extent (Malinow et al. 1994), increased red blood cell turnover may lead to elevated plasma tHcy levels.

Treatment with folic acid normalizes the basal plasma homocysteine concentration in hyperhomocysteinemic patients with vascular disease, and even markedly reduces normal plasma homocysteine concentrations in non-folatedeficient healthy subjects (Brattstrom et al. 1994). In contrast, high doses of vitamin $\mathrm{B}_{12}$ have not been found to have any such homocysteine-lowering effect. Although we did not study whether there is any effect of supplementation of vitamins on plasma tHcy concentration during the gonadotropin treatment, prophylactic supplementation of folate during gonadotropin treatment may prevent an increase in tHcy levels.

In conclusion, our findings have indicated that the plasma fasting tHcy concentration in patients with $\mathrm{IHH}$ was low during the testosterone-deficient state as compared with the controls, and it increased significantly after gonadotropin treatment. On the one hand, our observations suggest that androgens may have indirect effects, secondary to anabolic effects, on plasma tHcy levels. On the other hand, further studies are needed to answer the question as to whether the increase in tHcy levels following gonadotropin treatment raises the risk of cardiovascular events.

\section{References}

Andersson A, Brattström L, Israelsson B, Isaksson A, Hamfelt A \& Hultberg B 1992 Plasma homocysteine before and after methionine loading with regard to age, gender, and menopausal status. European Journal of Clinical Investigation 22 79-87.

Araki A \& Sako Y 1987 Determination of free and total homocysteine in human plasma by high-performance liquid chromatography with fluorescence detection. Journal of Chromatography 422 43-52.

Arnadottir M, Hultberg B, Nilsson-Ehle P \& Thysell H 1996 The effect of reduced glomerular filtration rate on plasma total homocysteine concentration. Scandinavian Journal of Clinical and Laboratory Investigation 56 41-46.

Bhasin S, Storer TW, Berman N, Callegari C, Clevenger B, Phillips J, Bunnell TJ, Tricker R, Shirazi A \& Casaburi R 1996 The effects of supraphysiologic doses of testosterone on muscle size and strength in normal men. New England Journal of Medicine 335 1-7.
Brattstrom L, Lindgren A, Israelsson B, Andersson A \& Hultberg B 1994 Homocysteine and cysteine: determinants of plasma levels in middle-aged and elderly subjects. Journal of Internal Medicine $\mathbf{2 3 6}$ 633-641.

Cockcroft DW \& Gault MH 1976 Prediction of creatinine clearance from serum creatinine. Nephron 16 31-41.

Cook JG 1971 Creatinine assay in the presence of protein. Clinica Chimica Acta 32 485-486.

Dawson B \& Trapp RG 2001 Research questions about means in three or more groups. In Basic and Clinical Biostatistics, pp 161-183. Singapore: McGraw Hill Book Co.

Ebenbichler CF, Kaser S, Bodner J, Gander R, Lechleitner M, Herold M \& Patsch JR 2001 Hyperhomocysteinemia in bodybuilders taking anabolic steroids. European Journal of Internal Medicine $\mathbf{1 2}$ 43-47.

Giltay EJ, Hoogeveen EK, Elbers JM, Gooren LJ, Asscheman H \& Stehouwer CD 1998 Effects of sex steroids on plasma total homocysteine levels: a study in transsexual males and females. Journal of Clinical Endocrinology and Metabolism 83 550-553.

Jacobsen DW, Gatautis VJ, Green R, Robinson K, Savon SR, Secic M, Ji J, Otto JM \& Taylor LM Jr 1994 HPLC determination of total homocysteine and other thiols in serum and plasma: sex differences and correlation with cobalamin and folate concentrations in healthy subjects. Clinical Chemistry 40 873-881.

Jockenhovel F, Vogel E, Reinhardt W \& Reinwein D 1997 Effects of various modes of androgen substitution therapy on erythropoiesis. European Journal of Medical Research 2 293-298.

Katznelson L, Finkelstein JS, Schoenfeld AA, Rosenthal DI, Anderson EJ \& Klibanski A 1996 Increase in bone density and lean body mass during testosterone administration in men with acquired hypogonadism. Journal of Clinical Endocrinology and Metabolism $\mathbf{8 1}$ 4358-4365.

Malinow MR, Axthelm MK, Meredith MJ, MacDonald NA \& Upson BM 1994 Synthesis and transsulfuration of homocysteine in blood. Journal of Laboratory and Clinical Medicine 123 421-429.

van der Mooren MJ, Wouters MG, Blom HJ, Schellekens LA, Eskes TK \& Rolland R 1994 Hormone replacement therapy may reduce high serum homocysteine in postmenopausal women. European Journal of Clinical Investigation 24 733-736.

Mudd SH \& Poole JR 1975 Labile methyl balances for normal humans on various dietary regimens. Metabolism 24 721-735.

Selhub J, Jacques PF, Wilson PW, Rush D \& Rosenberg IH 1993 Vitamin status and intake as primary determinants of homocysteinemia in an elderly population. Journal of the American Medical Association 270 2693-2698.

Ueland PM, Refsum H, Stabler SP, Malinow MR, Andersson A \& Allen RH 1993 Total homocysteine in plasma or serum: methods and clinical applications. Clinical Chemistry 39 1764-1779.

Wollesen F, Brattstrom L, Refsum H, Ueland PM, Berglund L \& Berne C 1999 Plasma total homocysteine and cysteine in relation to glomerular filtration in diabetes mellitus. Kidney International $\mathbf{5 5}$ 1028-1035

Yarali H, Yildirir A, Aybar F, Kabakci G, Bukulmez O, Akgul E \& Oto A 2001 Diastolic dysfunction and increased serum homocysteine concentrations may contribute to increased cardiovascular risk in patients with polycystic ovary syndrome. Fertility and Sterility 76 511-516.

Zar JH 1996 Paired-sample hypotheses. In Biostatistical Analysis. pp 163-179. New Jersey: Prentice Hall.

Zmuda JM, Bousserman LL, Maceroni D \& Thompson PD 1997 The effect of supraphysiologic doses of testosterone on fasting total homocysteine levels in normal men. Atherosclerosis 130 199-202.

Received in final form 26 June 2003

Accepted 9 July 2003

Made available online as an

Accepted Preprint 21 July 2003 